\title{
$\mathrm{BMJ}$ open Pre-pregnancy body mass index and the risk of adverse outcome in type 1 diabetic pregnancies: a population-based cohort study
}

\author{
Martina Persson, ${ }^{1}$ Dharmintra Pasupathy, ${ }^{2}$ Ulf Hanson, ${ }^{3}$ Magnus Westgren, ${ }^{1}$ \\ Mikael Norman ${ }^{1}$
}

To cite: Persson $\mathrm{M}$, Pasupathy D, Hanson U, et al. Pre-pregnancy body mass index and the risk of adverse outcome in type 1 diabetic pregnancies: a population-based cohort study. BMJ Open 2012;2: e000601. doi:10.1136/ bmjopen-2011-000601

- Prepublication history for this paper is available online. To view these files please visit the journal online (http:// dx.doi.org/10.1136/ bmjopen-2011-000601).

Received 10 November 2011 Accepted 20 January 2012

This final article is available for use under the terms of the Creative Commons Attribution Non-Commercial 2.0 Licence; see http://bmjopen.bmj.com

\footnotetext{
${ }^{1}$ Department of Clinical Science, Intervention and Technology, Karolinska Institute, Stockholm, Sweden ${ }^{2}$ Division of Women's Health, NIHR Biomedical Research Centre, Kings Health's Partners, King's College London, London, UK ${ }^{3}$ Department of Woman and Child Health, Uppsala University, Uppsala, Sweden
}

Correspondence to Dr Martina Persson; martina.persson@ki.se

\begin{abstract}
Objective: To assess the risk of perinatal complications in overweight and obese women with and without type 1 diabetes (T1DM).

Design: Prospective population-based cohort study. Setting: This study was based on data from the Swedish Medical Birth Registry from 1998 to 2007.

Participants: 3457 T1DM and 764498 non-diabetic pregnancies were included. T1DM was identified based on ICD code 024.0. Mothers were categorised according to pre-pregnancy body mass index (BMI: weight in kilograms per height in square metres) as normal weight (BMI 18.5-24.9), overweight (BMI 25-29.9) or obese $(\mathrm{BMI} \geq 30)$. Only women with singleton pregnancies and with data on BMI were included.
\end{abstract}

Primary/secondary outcomes: The primary outcome was large for gestational age (LGA: birth weight $>90$ th percentile) infants. Secondary outcomes were major malformations, pre-eclampsia (PE), preterm delivery, perinatal mortality, delivery by Caesarean section and neonatal overweight. Logistic regression analysis was performed with normal weight non-diabetic women as the reference category and also within the diabetic cohort with normal weight type 1 diabetic women as the reference. The ORs were adjusted for ethnicity, maternal age, height, parity, smoking and chronic hypertension.

Results: $35 \%$ of women with T1DM were overweight and $18 \%$ were obese, as compared with $26 \%$ and $11 \%$, respectively, in non-diabetic pregnancies. The incidences of adverse outcome increased with greater BMI category. As compared with non-diabetic normal weight women, the adjusted OR for obese T1DM for LGA was $13.26(95 \% \mathrm{Cl} 11.27$ to 15.59), major malformations $4.11(95 \% \mathrm{Cl} 2.99$ to 5.65$)$ and $\mathrm{PE}$ $14.19(95 \% \mathrm{Cl} 11.50$ to 17.50$)$. T1DM was a significant effect modifier of the association between $B M I$ and $L G A$, major malformations and PE $(p<0.001)$.

Conclusion: High pre-pregnancy BMI is an important risk factor for adverse outcome in type 1 diabetic pregnancies. The combined effect of both T1DM and overweight or obesity constitutes the greatest risk. It seems prudent to strive towards normal prepregnancy BMI in women with T1DM.

\section{ARTICLE SUMMARY}

Article focus

- To assess the risk of obstetric and perinatal complications in overweight and obese women with and without type 1 diabetes (T1DM).

Key messages

- High pre-pregnancy body mass index (BMI) is an important risk factor for adverse outcome in type 1 diabetic pregnancies.

- The combined effect of both T1DM and overweight or obesity constitutes the greatest risk.

- T1DM is a significant effect modifier of the association between BMI and large for gestational age, major malformations and pre-eclampsia $(p<0.001)$.

Strengths and limitations of this study

- The present study is to our knowledge, the first to present risk estimates of several obstetric and perinatal complications in women with T1DM, stratified by BMI category and compared with a non-diabetic reference population. The population-based study design, including a very large cohort of T1DM pregnancies, offers a unique possibility to provide solid data on risks associated with high BMI, including comparatively rare outcomes such as perinatal mortality. A potential limitation is that the study design did not allow assessment of the impact of maternal glycaemic control on the association between exposure and outcome.

\section{INTRODUCTION}

Body mass index (BMI) has increased among fertile women in many countries, including Sweden. ${ }^{1}$ Maternal overweight and obesity are well-known risk factors for adverse pregnancy outcome. High pre-pregnancy BMI has been associated with increased risk for stillbirth, fetal malformations, large for date neonates, neonatal and infant death, pregnancy-induced hypertension and preeclampsia (PE), maternal diabetes, delivery 
by Caesarean section as well as increased numbers of days spent in hospital for both mother and infant. ${ }^{2-11}$ The pathophysiological mechanism behind the increased risk of adverse pregnancy outcome in obese women is not fully understood. Increased insulin resistance and a state of inflammation associated with obesity $^{12}$ are likely important contributing factors.

Given the links between overweight, insulin resistance and adverse pregnancy outcome, any additional pregnancy risks in overweight women with diabetes are important to disclose, especially since overweight and obesity are more prevalent among diabetic women than in the general obstetric population. ${ }^{13}$ Increased risks of neonatal and maternal morbidity have been reported in overweight and obese women with gestational diabetes. ${ }^{14-16}$ In contrast, data are very limited regarding the impact of high maternal BMI on the risk of adverse pregnancy outcome in women with type 1 diabetes (T1DM). An interaction between maternal diabetes, including both pregestational and gestational diabetes, and obesity has been suggested to increase the risk of malformations in the offspring. ${ }^{17}$ However, the majority of women in that study had gestational diabetes and no separate analysis was performed in women with T1DM.

The aim of the present study was to analyse the association between maternal overweight and obesity and the risk of fetal and obstetric complications in type 1 diabetic pregnancies, with special reference to the high and increasing incidence of large for gestational age infants. ${ }^{13}$ This study includes a large national cohort of more than 3000 type 1 diabetic pregnancies, and the risk of adverse outcome in relation to maternal BMI was also compared with non-diabetic pregnancies. Our hypothesis was that maternal overweight/obesity and maternal T1DM have independent impact on the risk of adverse outcome and that the combination of the two constitutes the greatest risk.

\section{RESEARCH DESIGN, MATERIALS AND METHODS}

This population-based cohort study was based on data from the Swedish Medical Birth Registry (MBR). The MBR prospectively collects information on maternal medical history, obstetric and neonatal diagnoses and covers more than $99 \%$ of all pregnancies in Sweden. Until 2008, the MBR did only collect data on pregnancies from $28^{0 / 7}$ weeks of gestation and did not register data on earlier fetal losses or induced abortions. The quality of data in the registry is continuously evaluated by the National Board of Health and the conclusion of the latest extensive validation in 2002 was that quality of data is high. ${ }^{18}$ Maternal and neonatal diagnoses were classified according to ICD-10, introduced in Sweden in 1997. ICD-9 codes were also included to ensure that no patients would be missed. All diagnoses were made by a physician before hospital discharge and copies of the records were forwarded to the MBR. Maternal characteristics included in the present study were mother's age, parity, pre-pregnancy weight, height, chronic hypertension, smoking habits and whether the mother was born in one of the Nordic countries (Sweden, Finland, Denmark, Norway or Iceland) or elsewhere. Chronic hypertensive disease ICD-10 I10 or O10.0) was defined as blood pressure above 140/90 mm $\mathrm{Hg}$ diagnosed before pregnancy or before 20 weeks of gestation. Maternal height and pre-pregnancy weight were recorded by recall, and BMI was calculated as weight in kilograms divided by the square of the height in metres. Exposure in women with and without T1DM was defined as overweight $\left(\mathrm{BMI} \geq 25-29.9 \mathrm{~kg} / \mathrm{m}^{2}\right.$ ) or obese (BMI $\geq 30 \mathrm{~kg} / \mathrm{m}^{2}$ ), and pregnancy outcomes were compared with that of normal weight women (BMI $18.5-24.9 \mathrm{~kg}$ / $\mathrm{m}^{2}$ ). Women with $\mathrm{BMI}<18.5 \mathrm{~kg} / \mathrm{m}^{2}$ (under weight) and records with missing data on BMI were excluded as well as records with extreme values on maternal age $(<13$ or $>54$ years $)$, maternal weight $(<40$ or $>200 \mathrm{~kg})$ or maternal height $(<120$ or $>200 \mathrm{~cm})$. We applied the same limits for data acceptance of birth weight and birth length as in the National Perinatal Quality Registry in Sweden: that is, records with birth weight $<200$ or $>9998 \mathrm{~g}$ or birth length $<15$ or $>65 \mathrm{~cm}$, were excluded.

\section{Study cohort}

Infants from singleton pregnancies and born to mothers with T1DM in Sweden between 1998 and 2007 were included, in total $n=3457$. Type 1 diabetic pregnancies were identified based on ICD-10 code O240 and ICD-9 code 250 for pregestational diabetes.

\section{Non-diabetic cohort}

The reference group $(n=764498)$ included all singleton pregnancies to mothers without a diagnosis of diabetes (based on ICD-10 and -9 codes for T1DM (O240, $250 \times 1 / \times 3)$, type 2 diabetes $(\mathrm{O} 241)$ and all codes starting with E11 and E $177-119,250 \times 0 / \times 2$ or gestational diabetes codes (O244 A, B, X, 648.8)) and born in the same time period as the study cohort. Percentiles for birth weight were based on all live born, singleton infants, without major malformations to mothers without a diagnosis of diabetes. Birthweight percentiles were adjusted for sex and gestational age.

\section{Primary outcome}

Fetal macrosomia, that is, giving birth to a large for gestational age (LGA) infant, was the primary outcome of this study. LGA was defined as a birth weight $>90$ th percentile for sex and gestational age.

\section{Secondary outcomes}

Secondary outcomes were major malformations, PE, preterm delivery, perinatal mortality, delivery by Caesarean section (emergency and elective) and neonatal overweight. Major malformations were predefined in the MBR as fatal or potentially life-threatening malformations or if the malformation would likely lead to a serious handicap or major cosmetic defect if not surgically corrected. PE was defined as a blood pressure 
above 140/90 mm $\mathrm{Hg}$ after 20 weeks of gestation and proteinuria (at least $0.3 \mathrm{~g} /$ day or $>1+$ on a urine dipstick, ICD-10 codes: O14.0, O14.1 and O15/ICD-9 codes: 642.4, 642.5 and 642.6). Preterm birth was defined as delivery before 37 gestational weeks. Perinatal mortality was defined as intrauterine death after $28^{0 / 7}$ weeks of gestation or death during the first week of postnatal life. Neonatal overweight was defined as birth weight and ponderal index (PI, birth weight in grams per length in cubic centimetres) above the 90th percentile for sex and gestational age.

This study was approved by the Regional Ethical Review Board in Uppsala, Sweden.

\section{Statistical methods}

Comparison between groups were made using KruskalWallis test for continuous data and $\chi^{2}$ test and $\chi^{2}$ test for trend for binary and categorical data as appropriate. Unconditional logistic regression was used to explore associations between maternal BMI categories and adverse outcomes with normal weight (BMI 18.5$24.9 \mathrm{~kg} / \mathrm{m}^{2}$ ) women as the reference category as follows: the ORs of adverse outcomes in relation to BMI category were estimated in women with T1DM with (1) normal weight women with T1DM as reference category and (2) normal weight non-diabetic women as reference category. Crude and adjusted ORs were calculated. The following variables were included in the final model for LGA as possible confounders/covariates: Nordic origin (yes/no), maternal age, height, parity, smoking and chronic hypertension. The final regression models for the secondary outcomes included covariates significantly associated with the outcomes in univariate analysis. Missing indicator variables were used for maternal age and height. The likelyhood ratio test was used to explore potential interaction between BMI categories and T1DM for the risk of the adverse outcomes. A p value $<0.05$ was considered significant. All statistical analyses were performed using STATA 10.1 SE.

\section{RESULTS}

Between 1998 and 2007, there were 947096 deliveries in Sweden, including $4208(0.4 \%)$ deliveries to mothers with T1DM. Of all pregnancies, we excluded 441 records $(0.05 \%)$ with extreme values on maternal age, maternal weight or height. No records were excluded due to extreme values on birth weight, but 3402 records were missing for this variable. We excluded 90 records $(0.01 \%)$ due to extreme values on birth length and 14544 were missing for birth length. In women with T1DM, 652 records $(15 \%)$ were excluded due to missing data on maternal BMI or BMI $<18.5$ and $116(2.8 \%)$ due to multiple pregnancies. Seventeen records were identified as both missing for BMI and with multiple pregnancies, thus giving a final study cohort of 3457 infants (1758 male infants, $51 \%$ ) born to mothers with T1DM. The reference population included 764498 singleton pregnancies to mothers without a diagnosis of diabetes, excluding 28018 records from multiple pregnancies and 147835 records with missing data on maternal BMI or BMI $<18.5$.

Reference percentiles for birth weight, birth length and PI were formed using records from all non-diabetic pregnancies and excluding stillborn infants $(0.31 \%)$, infants with major malformations $(1.84 \%)$ and multiple pregnancies $(3.01 \%)$.

\section{Maternal and infant characteristics}

Mothers with T1DM had a significantly higher median pre-pregnancy BMI $\left(25.1 \mathrm{~kg} / \mathrm{m}^{2}\right)$ compared with the non-diabetic group $\left(23.6 \mathrm{~kg} / \mathrm{m}^{2}, \mathrm{p}<0.001\right)$. In the type 1 diabetic cohort, $35 \% \quad(n=1195)$ of women were overweight and $18 \%(n=618)$ were obese as compared with $26 \%(\mathrm{n}=200600)$ and $11 \%(\mathrm{n}=82331)$, respectively, in the non-diabetic population. Women with T1DM were also more often of Nordic origin and had a higher prevalence of chronic hypertension and smoking during the first trimester compared with women without diabetes ( $p$ value for all comparisons $<0.01$ ). Infants to mothers with T1DM were born at a significantly lower median gestational age, and preterm birth was four times as common compared with non-diabetic offspring ( $p$ value for all comparisons $<0.001$ ). The median birth weight was significantly higher in infants delivered by mothers with T1DM than in the reference group, table 1.

\section{Adverse outcomes in relation to BMI category}

Overall, the incidence of all adverse outcomes was significantly higher in women with T1DM, irrespective of BMI category. The incidence of the primary outcome LGA was highest in obese type 1 diabetic women; however, the differences between BMI categories did not reach statistical significance within the diabetes cohort. The incidence of all secondary outcomes was highest in obese women with T1DM, except for perinatal mortality in type 1 diabetic pregnancies with the highest recorded frequency in overweight women. Within the non-diabetic pregnancies, the incidence of all outcomes increased significantly with greater BMI category $\left(\chi^{2}\right.$ for trends for all outcomes $\mathrm{p}<0.001$ ) (table 2).

There was a similar pattern of increasing OR for adverse outcome with greater BMI category in women with and without T1DM. Inclusion of maternal covariates in the regression models did not significantly change these estimates. Relative to a normal weight non-diabetic woman, the adjusted OR for the risk of having a LGA infant in overweight or obese women with T1DM was approximately 13 as compared with approximately 2 in overweight and obese non-diabetic women, table 3 . In relation to a normal weight woman without diabetes, obesity in women with T1DM was associated with an adjusted OR for major malformation of 4.11 (95\% CI 2.99 to 5.65 ) as compared with 1.15 (95\% CI 1.09 to $1.22)$ in non-diabetic women with obesity. Compared with a normal weight non-diabetic woman, the adjusted ORs for PE in a woman with T1DM of normal weight was 
Table 1 Maternal and infant characteristics, type 1 diabetes and non-diabetic reference population

\begin{tabular}{|c|c|c|c|}
\hline & $\begin{array}{l}\text { Type } 1 \text { diabetes, } \\
\mathrm{N}=3457\end{array}$ & $\begin{array}{l}\text { Non-diabetic population, } \\
\mathrm{N}=764498\end{array}$ & p Value* \\
\hline \multicolumn{4}{|l|}{ Maternal characteristics } \\
\hline Nordic, n (\%) & $3194(92)$ & $643608(84)$ & $<0.001$ \\
\hline Swedish origin, $\mathrm{n}(\%)$ & 3151 (91) & $628534(82)$ & $<0.001$ \\
\hline Maternal age, years (median, IQR) & $30(27-34)$ & $30(27-33)$ & $<0.001$ \\
\hline Smoking first trimester, $\mathrm{n}(\%)$ & $384(11)$ & $72766(10)$ & 0.001 \\
\hline Primipara, n (\%) & $1559(45)$ & $337199(44)$ & 0.242 \\
\hline BMI, $\mathrm{kg} / \mathrm{m}^{2}$ (median, IQR) & $25.1(23.0-28.4)$ & $23.6(21.6-26.4)$ & $<0.001$ \\
\hline Overweight (BMI $\geq 25-29.9), \mathrm{n}(\%)$ & $1195(35)$ & $200600(26)$ & $<0.001$ \\
\hline Obese (BMI $\geq 30), n(\%)$ & $618(18)$ & $82331(11)$ & $<0.001$ \\
\hline Height, cm (median, IQR) & $167(162-170)$ & $167(162-170)$ & 0.250 \\
\hline Chronic hypertension, $\mathrm{n}(\%)$ & $92(2.7)$ & $2472(0.32)$ & $<0.001$ \\
\hline \multicolumn{4}{|l|}{ Infant characteristics } \\
\hline Male, n (\%) & $1758(51)$ & $393324(51)$ & 0.485 \\
\hline Gestational age, weeks (median, IQR) & $38(37-39)$ & $40(39-41)$ & $<0.001$ \\
\hline Preterm delivery, $\mathrm{n}(\%)$ & $741(21)$ & $35878(4.7)$ & $<0.001$ \\
\hline Birth weight, g (median, IQR) & $3805(3350-4265)$ & $3575(3240-3915)$ & $<0.001$ \\
\hline Birth length, cm (median, IQR) & $51(49-52)$ & $51(49-52)$ & 0.576 \\
\hline LGA, BW >90 percentile, $n(\%)$ & $1694(49)$ & $81142(11)$ & $<0.001$ \\
\hline AGA, BW $10-90$ percentile, $n(\%)$ & $1661(48)$ & $614784(80)$ & $<0.001$ \\
\hline SGA, BW $<10$ percentile, $n(\%)$ & 109 (3.2) & $76214(10)$ & $<0.001$ \\
\hline
\end{tabular}

7.17 (95\% CI 6.04 to 8.50$)$ and in combination with overweight 9.91 (95\% CI 8.61 to 11.40$)$ and in obese type 1 diabetic women, the adjusted OR was 14.19 (95\% CI 11.50 to 17.50$)$. The corresponding estimates for a nondiabetic woman with overweight or obesity were 1.74 (95\% CI 1.69 to 1.80 ) and 3.37 (95\% CI 3.25 to 3.49 ), respectively. The OR for Caesarean section increased with BMI category, both in women with and without T1DM, table 3 .

Table 4 shows the OR for adverse outcome in women with T1DM by BMI category with normal weight women with T1DM as the reference category. In obese type 1

Table 2 Perinatal outcomes for pregnant women with or without type 1 diabetes and stratified on pre-pregnancy BMI

\begin{tabular}{|c|c|c|c|c|}
\hline & BMI 18.5-24.9 & BMI 25-29.9 & $B M I \geq 30$ & p Value* \\
\hline \multicolumn{5}{|l|}{ LGA infant } \\
\hline Type 1 diabetes & $778(47)$ & $603(50)$ & $313(51)$ & 0.170 \\
\hline Non-diabetic & 39265 (8.2) & 26828 (13) & 15049 (18) & $<0.001$ \\
\hline \multicolumn{5}{|l|}{ Major malformations } \\
\hline Type 1 diabetes & $65(4.0)$ & $44(3.7)$ & $41(6.6)$ & 0.008 \\
\hline Non-diabetic & $8186(1.7)$ & 3736 (1.9) & $1610(2.0)$ & $<0.001$ \\
\hline \multicolumn{5}{|l|}{ Pre-eclampsia } \\
\hline Type 1 diabetes & $222(14)$ & $185(15)$ & $114(18)$ & 0.012 \\
\hline Non-diabetic & $9872(2.1)$ & 6529 (3.3) & $4810(5.8)$ & $<0.001$ \\
\hline \multicolumn{5}{|l|}{ Preterm delivery } \\
\hline Type 1 diabetes & $322(20)$ & $275(23)$ & $144(23)$ & 0.041 \\
\hline Non-diabetic & $21714(4.5)$ & $9464(4.7)$ & $4700(5.7)$ & $<0.001$ \\
\hline \multicolumn{5}{|l|}{ Perinatal mortality } \\
\hline Type 1 diabetes & $14(0.85)$ & $15(1.3)$ & $6(0.97)$ & 0.566 \\
\hline Non-diabetic & $1554(0.32)$ & $948(0.47)$ & $593(0.72)$ & $<0.001$ \\
\hline \multicolumn{5}{|l|}{ Caesarean section } \\
\hline Type 1 diabetes & $748(46)$ & $639(53)$ & $362(59)$ & $<0.001$ \\
\hline Non-diabetic & $64131(13)$ & $34081(17)$ & $18166(22)$ & $<0.001$ \\
\hline \multicolumn{5}{|l|}{ Neonatal overweight } \\
\hline Type 1 diabetes & $351(21)$ & $288(24)$ & $166(27)$ & 0.016 \\
\hline Non-diabetic & 15359 (3) & $10430(5)$ & $6466(8)$ & $<0.001$ \\
\hline
\end{tabular}

Data are presented as numbers (percentages).

${ }^{*} \chi^{2}$ test, Kruskal-Wallis test, $\chi^{2}$ test for trends.

BMI, body mass index; LGA, large for gestational age. 
Table 3 Crude and adjusted ${ }^{*}$ ORs $(95 \% \mathrm{Cl})$ for adverse perinatal outcomes in pregnant women with and without T1DM and stratified on pre-pregnancy BMI

\begin{tabular}{|c|c|c|c|c|}
\hline & BMI 18.5-24.9 & BMI 25-29.9 & BMI $\geq 30$ & Interaction p-value $\dagger$ \\
\hline \multicolumn{5}{|l|}{ LGA infant } \\
\hline \multicolumn{5}{|l|}{ T1DM } \\
\hline Crude & $10.16(9.10$ to 11.36$)$ & 12.40 (11.22 to 13.70$)$ & $12.29(10.50$ to 14.40$)$ & $<0.001$ \\
\hline Adjusted & 10.72 (9.56 to 12.01$)$ & 13.55 (12.23 to 15.02$)$ & 13.26 (11.27 to 15.59$)$ & $<0.001$ \\
\hline \multicolumn{5}{|l|}{ Non-diabetic } \\
\hline Crude & 1.0 & 1.74 (1.71 to 1.77$)$ & 2.52 (2.47 to 2.57 ) & $<0.001$ \\
\hline Adjusted & 1.0 & 1.76 (1.73 to 1.79$)$ & 2.60 (2.55 to 2.66$)$ & $<0.001$ \\
\hline \multicolumn{5}{|c|}{ Major malformations } \\
\hline \multicolumn{5}{|l|}{ T1DM } \\
\hline Crude & $2.28(1.71$ to 3.04$)$ & 2.34 (1.81 to 3.02$)$ & 4.11 (2.99 to 5.65$)$ & 0.03 \\
\hline Adjusted & $2.28(1.71$ to 3.04$)$ & 2.34 (1.81 to 3.03$)$ & 4.11 (2.99 to 5.65$)$ & 0.03 \\
\hline \multicolumn{5}{|l|}{ Non-diabetic } \\
\hline Crude & 1.0 & $1.10(1.06$ to 1.14$)$ & 1.15 (1.09 to 1.22$)$ & 0.03 \\
\hline Adjusted & 1.0 & $1.10(1.06$ to 1.14$)$ & 1.15 (1.09 to 1.22$)$ & 0.03 \\
\hline \multicolumn{5}{|l|}{ Pre-eclampsia } \\
\hline \multicolumn{5}{|l|}{ T1DM } \\
\hline Crude & 7.12 (6.02 to 8.42$)$ & 9.30 (8.11 to 10.67$)$ & $11.23(9.15$ to 13.77$)$ & $<0.001$ \\
\hline Adjusted & 7.17 (6.04 to 8.50$)$ & 9.91 (8.61 to 11.40$)$ & $14.19(11.50$ to 17.50$)$ & $<0.001$ \\
\hline \multicolumn{5}{|l|}{ Non-diabetic } \\
\hline Crude & 1.0 & $1.61(1.56$ to 1.66$)$ & 2.96 (2.86 to 3.07$)$ & $<0.001$ \\
\hline Adjusted & 1.0 & 1.74 (1.69 to 1.80$)$ & 3.37 (3.25 to 3.49$)$ & $<0.001$ \\
\hline \multicolumn{5}{|c|}{ Preterm delivery } \\
\hline \multicolumn{5}{|c|}{ T1DM } \\
\hline Crude & $4.86(4.22$ to 5.60$)$ & 6.23 (5.53 to 7.02$)$ & $6.39(5.30$ to 7.71$)$ & 0.16 \\
\hline Adjusted & $4.72(4.09$ to 5.44$)$ & 5.98 (5.31 to 6.74$)$ & 5.97 (4.94 to 7.21$)$ & 0.15 \\
\hline \multicolumn{5}{|l|}{ Non-diabetic } \\
\hline Crude & 1.0 & 1.05 (1.02 to 1.07$)$ & $1.28(1.24$ to 1.32$)$ & 0.16 \\
\hline Adjusted & 1.0 & 1.04 (1.02 to 1.07$)$ & 1.26 (1.22 to 1.30$)$ & 0.15 \\
\hline \multicolumn{5}{|c|}{ Perinatal mortality } \\
\hline \multicolumn{5}{|c|}{ T1DM } \\
\hline Crude & 2.55 (1.36 to 4.76$)$ & $3.93(2.49$ to 6.19$)$ & $3.14(1.40$ to 7.04$)$ & 0.29 \\
\hline Adjusted & $2.46(1.32$ to 4.60$)$ & 3.72 (2.36 to 5.89$)$ & $2.86(1.27$ to 6.44$)$ & 0.31 \\
\hline \multicolumn{5}{|l|}{ Non-diabetic } \\
\hline Crude & 1.0 & $1.47(1.35$ to 1.59$)$ & 2.24 (2.04 to 2.46$)$ & 0.29 \\
\hline Adjusted & 1.0 & $1.46(1.35$ to 1.59$)$ & 2.22 (2.03 to 2.44$)$ & 0.31 \\
\hline \multicolumn{5}{|c|}{ Caesarean section } \\
\hline \multicolumn{5}{|l|}{ T1DM } \\
\hline Crude & $5.59(5.00$ to 6.25$)$ & 7.09 (6.42 to 7.83$)$ & 9.44 (8.04 to 11.08$)$ & 0.42 \\
\hline Adjusted & 5.69 (5.09 to 6.37$)$ & 7.12 (6.44 to 7.88$)$ & 9.35 (7.95 to 11.00$)$ & 0.36 \\
\hline \multicolumn{5}{|l|}{ Non-diabetic } \\
\hline Crude & 1.0 & $1.33(1.31$ to 1.35$)$ & 1.84 (1.81 to 1.88$)$ & 0.42 \\
\hline Adjusted & 1.0 & 1.34 (1.32 to 1.36$)$ & 1.87 (1.83 to 1.90$)$ & 0.36 \\
\hline \multicolumn{5}{|c|}{ Neonatal overweight } \\
\hline \multicolumn{5}{|l|}{ T1DM } \\
\hline Crude & 8.46 (7.39 to 9.70$)$ & 9.93 (8.83 to 11.17$)$ & 11.71 (9.79 to 14.00$)$ & $<0.001$ \\
\hline Adjusted & 8.40 (7.32 to 9.64$)$ & 9.86 (8.76 to 11.11$)$ & 11.29 (9.42 to 13.53$)$ & $<0.001$ \\
\hline \multicolumn{5}{|l|}{ Non-diabetic } \\
\hline Crude & 1.0 & $1.66(1.62$ to 1.71$)$ & 2.59 (2.51 to 2.67$)$ & $<0.001$ \\
\hline Adjusted & 1.0 & 1.65 (1.61 to 1.69$)$ & 2.55 (2.48 to 2.63$)$ & $<0.001$ \\
\hline
\end{tabular}

Reference group: non-diabetic women with normal pre-pregnancy BMI.

*Adjusted for ethnicity, maternal age, height, parity, smoking first trimester and chronic hypertension.

†Interaction between BMI category and T1DM.

BMI, body mass index; LGA, large for gestational age; T1DM, type 1 diabetes.

diabetic women, the adjusted OR of major malformations (1.77 (95\% CI 1.18 to 2.65$))$ and PE (1.74 (95\% CI 1.35 to 2.25)) were significantly increased compared with normal weight type 1 diabetic women. The OR of Caesarean section was significantly increased in both overweight and obese type 1 diabetic women, table 4 . The OR for LGA did not differ significantly between the different BMI categories. However, the adjusted OR for delivering a disproportionate LGA infant with neonatal overweight (PI >90th percentile) was significantly 


\begin{tabular}{|c|c|c|c|}
\hline & \multicolumn{3}{|l|}{ T1DM } \\
\hline & BMI 18.5-24.9 & BMI 25-29.9 & $\mathrm{BMI} \geq 30$ \\
\hline \multicolumn{4}{|l|}{ LGA infant } \\
\hline Crude & 1.0 & $1.13(0.98$ to 1.32$)$ & $1.14(0.95$ to 1.37$)$ \\
\hline Adjusted & 1.0 & $1.18(1.01$ to 1.38$)$ & $1.21(1.00$ to 1.47$)$ \\
\hline \multicolumn{4}{|c|}{ Major malformations } \\
\hline Crude & 1.0 & $0.93(0.63$ to 1.37$)$ & $1.73(1.15$ to 2.58$)$ \\
\hline Adjusted & 1.0 & $0.92(0.62$ to 1.36$)$ & 1.77 (1.18 to 2.65$)$ \\
\hline \multicolumn{4}{|c|}{ Pre-eclampsia } \\
\hline Crude & 1.0 & $1.17(0.95$ to 1.45$)$ & $1.45(1.13$ to 1.86$)$ \\
\hline Adjusted & 1.0 & $1.21(0.98$ to 1.50$)$ & 1.74 (1.35 to 2.25$)$ \\
\hline \multicolumn{4}{|c|}{ Preterm delivery } \\
\hline Crude & 1.0 & $1.23(1.02$ to 1.47$)$ & 1.25 (1.00 to 1.56$)$ \\
\hline Adjusted & 1.0 & $1.22(1.02$ to 1.47$)$ & 1.25 (1.00 to 1.56$)$ \\
\hline \multicolumn{4}{|c|}{ Perinatal mortality } \\
\hline Crude & 1.0 & $1.48(0.71$ to 3.08$)$ & $1.14(0.44$ to 2.98$)$ \\
\hline Adjusted & 1.0 & $1.47(0.70$ to 3.03$)$ & 1.08 (0.41 to 2.83$)$ \\
\hline \multicolumn{4}{|c|}{ Caesarean section } \\
\hline Crude & 1.0 & $1.38(1.19$ to 1.60$)$ & $1.69(1.40$ to 2.04$)$ \\
\hline Adjusted & 1.0 & $1.37(1.18$ to 1.60$)$ & 1.67 (1.38 to 2.03$)$ \\
\hline \multicolumn{4}{|c|}{ Neonatal overweight } \\
\hline Crude & 1.0 & $1.17(0.98$ to 1.40$)$ & 1.35 (1.09 to 1.67$)$ \\
\hline Adjusted & 1.0 & 1.19 (0.99 to 1.42$)$ & 1.36 (1.09 to 1.69$)$ \\
\hline
\end{tabular}

increased in obese type 1 diabetic women 1.36 (95\% CI 1.09 to 1.69$)$.

\section{DISCUSSION}

This study shows that high maternal pre-pregnancy BMI is a very important risk factor for adverse pregnancy outcome in women with and without T1DM. High maternal BMI and T1DM are independent risk factors for maternal and perinatal complications. However, T1DM remains a stronger risk factor for adverse outcome than obesity. The risk of adverse outcome in women with concomitant T1DM and obesity exceeds that of either condition alone, indicating synergism between the two exposures. Obesity in T1DM is associated with significantly increased risk of PE, major malformations, neonatal overweight and Caesarean section as compared with type 1 diabetic women with normal BMI.

The prevalence of overweight and obesity in pregnant women is increasing in Sweden and worldwide, ${ }^{12}$ and the harmful effects of high maternal BMI on pregnancy outcome are well established in the general obstetric population. $^{2-11}$ On the other hand, data on the potential association between high maternal BMI and adverse pregnancy outcome in women with T1DM is scarce. ${ }^{17} 1920$ In a cohort of 46 women with T1DM and nephropathy, maternal overweight was identified as an important risk factor for poor pregnancy outcome. ${ }^{19}$ In mixed populations of women with pregestational diabetes, maternal obesity has been associated with pregnancy complications $^{20}$ and increased risk of birth defects. ${ }^{17}$ These two studies however do not separate women with diabetes type 1 from those with diabetes type 2 and do not include any comparable data from a non-diabetic reference population.

The present study is to our knowledge the first to present risk estimates of obstetric and perinatal complications in a large cohort of women with exclusively T1DM, stratified by BMI category and compared with a non-diabetic reference population. The large sample size enabled risk estimation of rare outcomes such as perinatal mortality and major malformations in relation to subgroups of maternal BMI. The population-based study design provides unanimous risk estimates for overweight and obese women with and without T1DM. The vast majority of our study population is of Nordic origin and $91 \%$ were Swedish. The study population is also homogenous with respect to medical care in pregnancy. In Sweden, healthcare is free of charge as well as insulin, test strips for home monitoring of glucose and equipment for insulin administration. The care of pregnant women with T1DM is uniform over the whole country and pregnancy outcome does not differ with geographical area. ${ }^{13}$

Some limitations with the present study should be noted. BMI was calculated from recalled data on prepregnancy weight and height. Women tend to underestimate their weight, and it has been demonstrated that this bias increases directly with the degree of overweight. $^{21}$ A potential misclassification of women to lower BMI categories would lead to an underestimation of our 
findings of increased risks associated with high maternal BMI. The Swedish MBR does not collect data on maternal glycaemic control, duration of diabetes and insulin regimens or data on diet and physical activity. Data on socioeconomic factors are also very limited. Consequently, the impact of socioeconomic factors, diet, physical activity and level of control on the risk of adverse outcome could not be assessed. It is plausible that the achieved level of metabolic control differed between normal weight, overweight and obese type 1 diabetic women. In a study on pregnancies complicated by gestational diabetes, the fasting glucose levels were significantly higher in obese compared with overweight and normal weight women. ${ }^{14}$ However, results from the HAPO study confirm that maternal BMI and glycaemia exert independent effects on the risk of adverse pregnancy outcome. ${ }^{2}$

In the present study, obese women with T1DM had significantly increased risks of major malformations and $\mathrm{PE}$ as compared with normal weight women with T1DM. This is in line with the finding of an interaction between maternal diabetes and obesity on the risk of adverse outcome in a mixed population of women with different types of diabetes. ${ }^{17}$ However, the increased risk of major malformations in relation to BMI in the present analysis should be interpreted with caution as maternal overweight and obesity rend ultrasound assessment of fetal anatomy difficult, ${ }^{22}$ and we do not have data on the number of induced abortions due to malformations. Maternal hyperglycaemia in early pregnancy is a wellknown risk factor for major malformations and PE. ${ }^{23}$ Obesity is associated with increased insulin resistance, ${ }^{12}$ and one could speculate that women with obesity had a poorer level of control in early pregnancy than women with normal or slightly elevated BMI. In line with previous studies, we found increased risks of PE and major malformations in obese non-diabetic women. ${ }^{5}{ }^{610}$ In the present study, the risks of these complications were also significantly elevated in non-diabetic women with overweight. Obesity is associated with decreased insulin sensitivity, and already slightly elevated levels of fasting glucose, within the upper normal range, are associated with increased risk of PE in women without diabetes. ${ }^{24}$ In Sweden, there is no uniform screening for gestational diabetes. It is possible that the increased risk of $\mathrm{PE}$ and major malformations in overweight and obese women in the reference group is partly due to undetected cases of impaired glucose tolerance or diabetes. Interestingly, maternal pre-pregnancy BMI has been demonstrated as a stronger predictor of major malformations than severity of gestational diabetes. ${ }^{25}$

In women with T1DM, the incidence of LGA was very high in all weight classes and increased with greater BMI category. However, the OR for an LGA outcome did not differ significantly between BMI categories, as opposed to in non-diabetic women. This is in accordance with findings in two recent studies. ${ }^{26}{ }^{27}$ On the contrary, the risk of delivering a disproportionate, overweight LGA infant (PI $>90$ th percentile) was significantly increased in obese women within the type 1 diabetic cohort. In accordance with the study by Ehrenberg, our findings indicate that maternal overweight is an important risk factor for LGA, but maternal diabetes has an even greater impact. ${ }^{28} \mathrm{~A}$ possible contributing factor to this finding could also be the increasing prevalence of $\mathrm{PE}$ with greater BMI category.

This study confirms the observations in non-diabetic pregnancies $^{2-5}$ that increasing maternal BMI is associated with increased risk of delivery by Caesarean section also in women with T1DM. The increased incidence of complications such as PE and LGA in these groups most likely contributes to this finding.

The majority of perinatal deaths were stillbirths in all BMI categories and in both women with and without T1DM. The risk of perinatal mortality was independent of BMI category within the type 1 diabetic cohort but increased significantly with higher BMI in the reference group. This finding is in line with previous studies, reporting increased risk of both stillbirth and neonatal mortality in obese non-diabetic women even after adjusting for maternal and perinatal risk factors. ${ }^{7-9}$ The lack of a significantly increased risk of perinatal mortality with increasing BMI category within the diabetes cohort indicate that diabetes is a stronger risk factor for perinatal mortality than maternal overweight/obesity.

In the present study, we found an increasing risk of preterm delivery with greater BMI category, both in women with and without T1DM. Results from some earlier studies have shown an increased risk of preterm delivery in obese non-diabetic women, ${ }^{3}{ }^{4}$ while others have reported the opposite association. ${ }^{25}$

It is hypothesised that the increased risk of pregnancy complications in overweight and obese women is related to increased maternal fat mass. In the present study, prepregnancy BMI was used as a proxy for maternal fat mass as there is a strong correlation $\left(\mathrm{r}^{2}=0.86\right)$ between prepregnancy BMI and maternal fat mass in women without diabetes. ${ }^{29}$ However, BMI does not provide information on the localisation of fat mass. One suggested link between high maternal pre-pregnancy BMI and increased risk of adverse outcome pregnancy is a large visceral fat mass. The visceral fat mass is associated with increased insulin resistance, inflammation and lipotoxicity with potential harmful effects on maternal vascular and placental function and fetal development. ${ }^{30}$ Other pathophysiological mechanisms behind the increased risk of adverse pregnancy outcome in overweight/obese mothers are not clear but are most likely complex. Genetic and socioeconomic factors, maternal diet and physical activity are probable contributing factors.

In conclusion, this population-based study on more than 3000 type 1 diabetic pregnancies demonstrates a strong association between maternal pre-pregnancy BMI and elevated risk of adverse pregnancy outcome. T1DM in combination with overweight or obesity constitutes a higher risk than either condition alone. 
Striving towards normal pre-pregnancy BMI in women with T1DM could hopefully reduce the risk of adverse outcome.

Acknowledgements This study was supported by the Swedish Order of Freemasons and the Stockholm County Council. DP was funded by the National Institute of Health Research (NIHR), UK, and the Tommy's Charity. The funding consisted of salary for the researchers MP and DP. We appreciate the help from the Swedish Medical Birth Registry to provide us with data.

Contributors MP, DP, UH, MW and MN: contributed to design and interpretation of data; MP and UH: data acquisition; MP and DP: data analyses; MP, DP, UH, MW and MN: interpretation of results; MP and MN: drafted the manuscript; MN: handled funding and supervision; MP, DP, UH, MW and MN: critical revision of the manuscript and final approval of the version to be published.

Funding This research received no specific grant from any funding agency in the public, commercial or not-for-profit sectors.

Competing interests None.

Ethics approval This study was approved by the Regional Ethical Review Board in Uppsala, Sweden. Date of approval: 22/7 2009, reference number: 2009/187.

Provenance and peer review Not commissioned; externally peer reviewed.

Data sharing statement No additional data available.

\section{REFERENCES}

1. Surkan $P$, Hsieh $C C$, Johansson $A L$, et al. Reasons for increasing trends in large for gestational age births. Obstet Gynecol 2004;104:4.

2. HAPO Study Cooperative Research Group. Hyperglycaemia and Adverse Pregnancy Outcome (HAPO) Study: associations with maternal body mass index. BJOG 2010;117:575-84.

3. Callaway LK, Prins JB, Chang AM, et al. The prevalence and impact of overweight and obesity in an Australian obstetric population. Med J Aust 2006;2:56-9.

4. Heslehurst N, Simpson H, Ells LJ, et al. The impact of maternal BMI status on pregnancy outcomes with immediate short-term obstetric resource implications: a meta-analysis. Obes Rev 2008;9:635-83.

5. Athukorala $\mathrm{C}$, Rumbold $\mathrm{AR}$, Willson $\mathrm{KJ}$, et al. The risk of adverse pregnancy outcomes in women who are overweight or obese. BMC Pregnancy Childbirth 2010;10:56.

6. Stothard KJ, Tennant PW, Bell R, et al. Maternal overweight and obesity and the risk of congenital anomalies: a systematic review and meta-analysis. JAMA 2009;301:636-50.

7. Kristensen $\mathrm{J}$, Vestergaard $\mathrm{M}$, Wisborg $\mathrm{K}$, et al. Pre-pregnancy weight and the risk of stillbirth and neonatal death. BJOG 2005;112:403-8.

8. Nohr EA, Vaeth $\mathrm{M}$, Bech $\mathrm{BH}$, et al. Maternal obesity and neonata mortality according to subtypes of preterm birth. Obstet Gynecol 2007:110:1083-90.

9. Cnattingius S, Bergström R, Lipworth L, et al. Prepregnancy weight and the risk of adverse pregnancy outcomes. $N$ Engl J Med 1998;338:147-52.
10. O'Brien TE, Ray JG, Chan WS. Maternal body mass index and the risk of preeclampsia: a systematic overview. Epidemiology 2003; $14: 368-74$.

11. Chen A, Feresu SA, Fernandez C, et al. Maternal obesity and the risk of infant death in the United States. Epidemiology 2009;20:74-81.

12. Catalano P. Obesity, insulin resistance, and pregnancy outcome. Reproduction 2010;140:365-71.

13. Persson M, Norman M, Hanson U. Obstetric and perinatal outcomes in type 1 diabetic pregnancies: a large, population-based study. Diabetes Care 2009;32:2005-9.

14. Roman AS, Rebarber A, Fox NS, et al. The effect of maternal obesity on pregnancy outcomes in women with gestational diabetes. J Matern Fetal Neonatal Med 2011;24:723-7.

15. Yogev $\mathrm{Y}$, Langer $\mathrm{O}$. Pregnancy outcome in obese and morbidly obese gestational diabetic women. Eur J Obstet Gynecol Reprod Biol 2008;137:21-6.

16. Langer O, Yogev $\mathrm{Y}$, Xenakis EM, et al. Overweight and obese in gestational diabetes: the impact on pregnancy outcome. Am J Obstet Gynecol 2005;192:1768-76.

17. Moore LL, Singer MR, Bradlee ML, et al. A prospective study of the risk of congenital defects associated with maternal obesity and diabetes mellitus. Epidemiology 2000;11:689-94.

18. The National Board of Health and Welfare (Socialstyrelsen). http:// www.sos.se/epc/fodelse/mfr.htm (accessed 18 Dec 2012).

19. Yogev $\mathrm{Y}$, Chen R, Ben-Haroush A, et al. Maternal overweight and pregnancy outcome in women with type 1 diabetes mellitus and different degrees of nephropathy. J Matern Fetal Neonatal Med 2010;23:999-1003.

20. Ray JG, Vermeulen MJ, Shapiro JL, et al. Maternal and neonatal outcomes in pregestational and gestational diabetes mellitus, and the influence of maternal obesity and weight gain: the DEPOSIT study. QJM 2001;94:347-56.

21. Rowland ML. Self-reported weight and height. Am J Clin Nutr 1990;52:1125-33.

22. Dashe JS, Mclntire DD, Twickler DM. Maternal obesity limits the ultrasound evaluation of fetal anatomy. $J$ Ultrasound Med 2009;28:1025-30.

23. Taylor R, Davidson JM. Type 1 diabetes and pregnancy. BMJ 2007;334:742-5.

24. The HAPO Study Cooperative research group. Hyperglycemia and adverse pregnancy outcomes. N Engl J Med 2008;358:1991.

25. Garcia-Patterson A, Erdozain L, Ginovart G, et al. In human gestational diabetes mellitus congenital malformations are related to pre-pregnancy body mass index and to severity of diabetes. Diabetologia 2004;47:509-14.

26. Murphy HR, Steel SA, Roland JM, et al. Obstetric and perinatal outcomes in pregnancies complicated by Type 1 and Type 2 diabetes: influences of glycaemic control, obesity and social disadvantage. Diabet Med 2011;28:1060-7.

27. Feghali M, Khoury JC, Timofeev J, et al. Asymmetric large for gestational age in newborns in pregnancies complicated by diabetes mellitus: is maternal obesity a culprit? J Matern Fetal Neonatal Med 2012;25:32-5.

28. Ehrenberg HM, Brian MM, Catalano P. The influence of obesity and diabetes on the prevalence of macrosomia. Am J Obstet Gynecol 2004;191:964-8.

29. Sewell MF, Huston-Presley L, Amini SB, et al. Body mass index: a true indicator of body fat in obese gravidas. $J$ Reprod Med 2007:52:907-11.

30. Jarvie E, Hauguel-de-Mouzon S, Nelson S, et al. Lipotoxicity in obese pregnancy and its potential role in adverse pregnancy outcome and obesity in the offspring. Clin Sci 2010;119:123-12. 